\title{
Inhibitory Effects of Momordin I Derivatives on the Formation of Fos-Jun-AP-1 DNA Complex
}

\author{
Juhyung Lee, Chi-Hoon Park, Wook-Hwan Kim, Yun Ha Hwang, Kyungchae Jeong, and Chul-Hak Yang \\ Department of Chemistry and Molecular Engineering, College of Natural Sciences, Seoul National University, \\ Seond151-747,Korea."E-mail: chulyang@plazasmiac.kr \\ Received February 13, 2006
}

\begin{abstract}
In our previous studies, we have observed that curcumin and momordin I isolated from Ampelopsis radix inhibit the formation of Fos-Jun-activation protein-1 ( $\Lambda \mathrm{P}-1) \mathrm{DN} \Lambda$ complex. We have screened more effective compounds which have a 5-membered ring framework like momordin I and have modified disaccharide or carboxylic acid portions in momordin I. We synthesized momordin I derivatives according to the published method with slight modification. Synthetic momordin I derivatives showed remarkable inhibitory activities on Fos-Jun- $\Lambda$ P-1 DN $\Lambda$ complex formation results in in vitro assays. The $\mathrm{IC}_{50}$ values of momordin I derivatives were about $4.0 \mu \mathrm{M}$ in an electrophoretic mobility shift assay (EMS $\Lambda$ ). This value is about 125 times higher than that of curcumin and about 12 times higher than that for curcumin derivative $\mathrm{C} 1$, and moreover about 30 times higher than that for momordin I. We found momordin I derivatives (a) and (b) are the strongest inlibitory compound for Fos-Jun- $\Lambda$ P-1 DN $\Lambda$ complex formation.
\end{abstract}

Key Words : Fos-Jun, Momordin I, Curcumin, AP-I, EMSA

\section{Introduction}

The transcription factor activation protein-1 (AP-1) regulates the transcription of various genes with the consensus DNA recognition sequences TGA(C/G)TCA designated as a TPA responsive element (TRE) in their promoter region.' The proto-oncogene products, Fos and Jun are members of the AP-1 family of the transcription factor and both belong to a family of leucine zipper proteins. These proteins dimerize via a structural motif known as the leucine zipper and bind to an AP- 1 DNA consensus sequence. Jun binds as a homodimer to the AP-1 DNA site, while Fos fails to dimerize and has no apparent affinity for the AP-1 element. But cotranslated Fos and Jun proteins bind more effectively to the AP-1 DNA site as a heterodimer than does the Jun homodimer ${ }^{2}$

The role of Fos-Jun oncogenic activation is a regulator of the final steps in signal transduction processes, such as tumor proliferation and differentiation. Therefore, inhibiting the formation of Fos-Jun-AP-1 DNA complex can be a reasonable tumor suppressing method from a transcriptional perspective.

Curcumin (diferuloylmethane) is known to have diverse biological functions, such as anti-inflammatory, anti-tumor, anti-oxidative, cytotoxic, antifungal, antibacterial, and antihepatotoxic activities. ${ }^{3}$ As explained in our previous report, curcumin and curcumin analogues showed an inhibitory effect on the formation of Fos-Jun-AP-1 DNA complex. ${ }^{4-7}$

In our previous experiment, momordin I was isolated from Ampelopsis radix and then assayed. ${ }^{4}$ Momordin I showed a remarkable result in its inhibition of the formation of FosJun-AP-1 DNA complex. So we tried to find more powerful compounds which have some structural similarities.

As shown in Figure 1, Momordin I consists of a five-

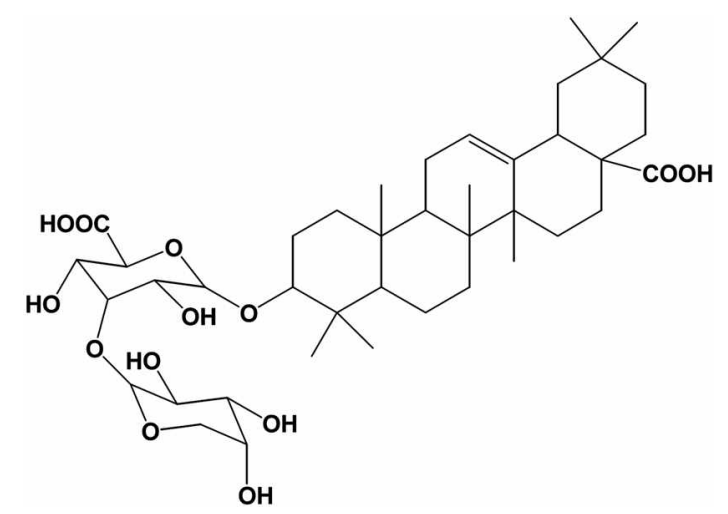

Figure 1. Chemical structure of momordin I. Momordin I was isolated from ethanol cxtracts of Ampelopsis radix. It contains a 5membered ring, disaccharide and carboxylic acid portions. The compound has three active functional portions. One is disaccharide, another is carboxylic acid, and the other is a double bond.

membered ring with disaccharide and carboxylic acid portions. Disaccharide and carboxylic acid pottions in momordin I were modified and synthesized according to a published synthetic method with slight modification. ${ }^{8}$ Inhibition activities were assayed by electrophoretic mobility shift assay (EMSA) and quantified by an image analyzing system (Nonlinear Ltd. in UK Phoretix TotolLab program). Comparison data were estimated with an $\mathrm{IC}_{50}$ (50\% inhibition concentration) value.

\section{Experimental Section}

Construction and purification of Fos and Jun proteins. A DNA-binding and Leucine zipper region of c-fos (rat) gene (amino acids 118-211) and c-jum (rat) gene (amino acids 228-334) were reconstructed with pET21c vector 
(Novagene) which contains a 6-histidine residue at a Cteminal region. ${ }^{9-11}$ The reconstructed $c-f o s$ and $c$-jun are referred to as $\mathrm{pJH}-\mathrm{Fos}$ and $\mathrm{pJH}-J u n$, respectively. $\mathrm{pJH}$-Fos and $\mathrm{pJH}-\mathrm{Jun}$ plasmid were transformed in $E$. coll $\mathrm{BL} 2 \mathrm{I}$ (DE3) and overexpressed using isopropyl $\beta$-D-thiogalactopyranoside (IPTG). Pelleted cells were solubilized in the presence of $8 \mathrm{M}$ urea and purified by nickel-chelate affinity resin (His-Bind Resin, Novagene). The purified proteins were renatured by an extensive dialysis against a dialysis buffer $(50 \mathrm{mM} \mathrm{NaCl}, 25 \mathrm{mM}$ Tris-HCl, pH 7.4, I mM EDTA, $1 \mathrm{mM}$ DTT) with a gradually decreasing concentration of urea. The purified $\mathrm{pJH}-\mathrm{Fos}$ and $\mathrm{pJH}-\mathrm{Jun}$ proteins had an apparent molecular mass of $15 \mathrm{kDa}$ and $17 \mathrm{kDa}$, respectively.

Electrophoretic mobility shift assay (EMSA). Purified $\mathrm{p} J \mathrm{H}-\mathrm{Fos}$ and $\mathrm{pJH}-\mathrm{Jun}$ proteins were mixed to a molar equivalent then incubated for dimerization of Fos-Jun heterodimer at room temperature for $30 \mathrm{~min}$. A ${ }^{32} \mathrm{P}$-labeled AP-I DNA probe was prepared by the standard radioactive 5 -temninal labeling method. 1.75 pmole $/ \mu \mathrm{L}$ of AP-1 consensus oligonucleotide (Promega) was mixed with $10 \mu \mathrm{Ci}$ $\left[\gamma^{32} \mathrm{P}\right]$ (Amersham), T4 polynucleotide kinase (Takara), and T4 polynucleotide kinase buffer. The above mixture was incubated at $37{ }^{\circ} \mathrm{C}$ for $30 \mathrm{~min}$. Unincorporated $\gamma_{-}^{32} \mathrm{P}$ ATP was removed by a G-25 spin column (Boehringer Mannheim). Chemicals, Fos-Jun heterodimer proteins and AP-I DNA probe were mixed and incubated at $37^{\circ} \mathrm{C}$ for $30 \mathrm{~min}$, then loaded on $6 \%$ polyacrylamide native gel. A Fos-Jun-AP-1 DNA complex band was detected in $x$-ray film by autoradiography and quantitatively interpreted using the TotalLab ${ }^{\mathrm{TM}}$ program (Nonlinear Dynamics Ltd., UK).

Synthesis of momordin I derivatives. Momordin I derivatives (a) and (b) were synthesized by the published method from uvaol. ${ }^{8}$ This is slightly modified. Uvaol was purchased from Sigma-Aldrich Chem. Co.

Derivative (a): A solution of $0.1 \mathrm{mM}$ (44.3 mg) uvaol in 3 $\mathrm{mL}$ pyridine was refluxed with $0.25 \mathrm{mM}(59.06 \mathrm{mg})$ phthalic anhydride for $24 \mathrm{~h}$. After cooling at room temperature, the mixture was solved in ethyl acetate and then diluted with $10 \%$ hydrochloric acid. An organic layer was obtained and washed with hot water. The organic layer was dried with sodium sulfate then precipitates were filtered off. After concentration, white crystals of (a) were obtained.

Derivative (b): Products of (a) were dissolved in acetone and mixed with $\mathrm{I} \mathrm{N} \mathrm{NaOH}$. The precipitates were filtered off, dissolved in ethyl acetate and then dried with sodjum sulfate. After concentration, white crystals of (b) were obtained.

\section{Results and Discussion}

Synthesis of momordin I derivatives. As shown in Figure 2 momordin I derivative (a) (Urs-12-ene-3 $\beta$,28-diol Dihemiphthalate) was synthesized according to the published method from uvaol. ${ }^{1} \mathrm{H}-\mathrm{NMR}\left(\mathrm{CDCl}_{3}\right): 3.80(\mathrm{~d}, 1 \mathrm{H}, J=$ $10 \mathrm{~Hz}, \mathrm{H}-28 \mathrm{a}), 4.40$ (d, $1 \mathrm{H}, J=10 \mathrm{~Hz}, \mathrm{H}-28 \mathrm{~b}), 4.76$ (dd, $1 \mathrm{H}$, $\left.J_{1}=\mathrm{I} 1, J_{2}=5 \mathrm{~Hz}, \mathrm{H}-3\right), 5.17(\mathrm{bt}, 1 \mathrm{H}, \mathrm{H}-12), 7.5-8.2(\mathrm{~m}, 8 \mathrm{H}$, Ar). IR (KBr): $1735,1290 \mathrm{~cm}^{-1}$ (ester); $1700 \mathrm{~cm}^{-1}$ (-COOH), m.p. $142-144^{\circ} \mathrm{C}$.

The sodium salt of Urs-12-ene-3 $\beta, 28$-diol Dihemiphthalate, Momordin I derivative (b) was dissolved in acetone and mixed with $1 \mathrm{~N} \mathrm{NaOH}$. IR (KBr): $1710,1280 \mathrm{~cm}^{-1}$ (ester); $1590,1570,1390 \mathrm{~cm}^{-1}$ (-COO), m.p. $250-253^{\circ} \mathrm{C}$.

Inhibitory effect of synthetic momordin I derivatives in Fos-Jun-AP-1 DNA complex. Curcumin and curcumin analogues $\mathrm{Cl}$ are known as inhibitors of Fos-Jun-AP-I DNA complex formation. ${ }^{57}$ And, as found in our previous report, momordin I which is isolated from Ampelopsis radix inhibits more effectively than curcumin does. ${ }^{4}$ Momordin I has three active sites, namely: disaccharide, carboxylic acid and the double bond in the $3^{\text {rd }}$ ring (Fig. 1). So we tried to find compounds which have structural similarities and modified active site groups in momordin $\mathrm{I}$. We assayed chemicals which have a five-membered ring framework like ursolic acid, uvaol, oleanolic acid, 18beta-glycynnetinic acid and friedelin, but no significant inhibitory activities were observed through these compounds. Disaccharide and carboxylic acid in momordin were substituted with phthalic

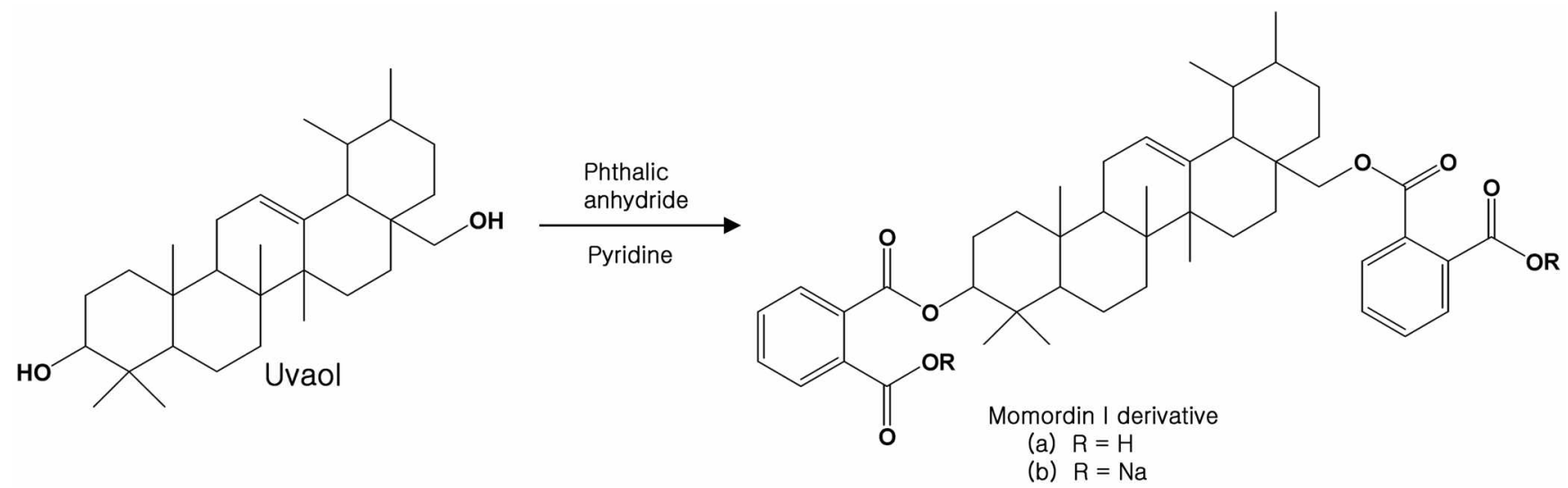

Figure 2. The synthesis of momordin I derivatives. Momordin I derivative (a) was synthesized by the following reaction. Uvaol was refluxed in pyridine with phthalic anhydride. Product (a) was mixed with sodium hydroxide in acetone resulting in momordin I $\times$ derivative (b) being formed. 


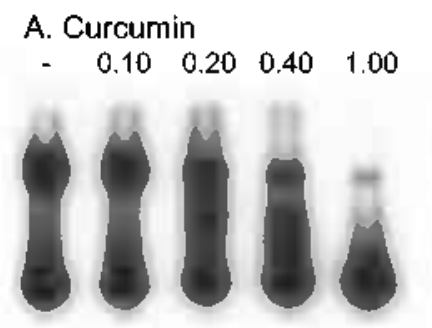

\section{B. Momordin 1}

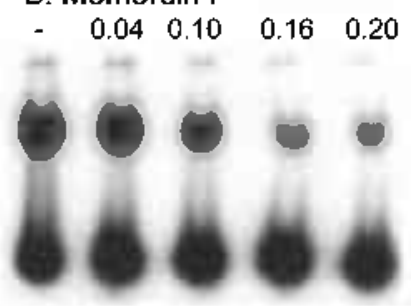

C. Curcumin derivative (C1)

D. Momordin derivative (a)

- 0.0020 .0040 .0060 .008
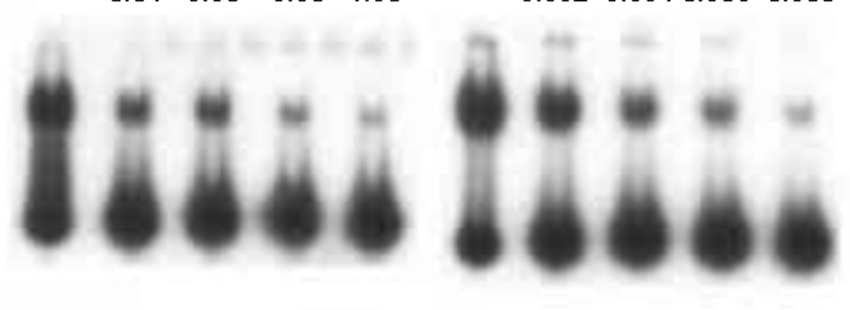

E. Momordin derivative (b)

- 0.0020 .0040 .0060 .008

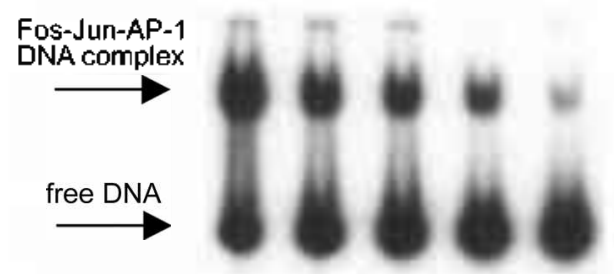

Figure 3. Autoradiogran of EMSA with several potent inhibitors. The bands of Fos-Jun- $\Lambda$ P-I DNA complex and unbounded free DNA are indicated. 32-P labeled AP-1 consensus DNA was used. Gradually increased concentrations of several potent inhibitors were mixed with Fos-Jun- $\Lambda$ P-1 DN $\Lambda$ solution. $(\Lambda)$ Curculnin $(0$, $0.1,0.2,0.4,1.0 \mathrm{mM}),(B)$ Momordin I $(0,0.04,0.10,0.16,0.20$ $\mathrm{mM})$, (C) Curcumin derivative (C1) $(0,0.04,0.06,0.08,0.10)$ (D) Momordin I derivative (a) $(0,0.002,0.004,0.006,0.008 \mathrm{mM}),(\mathrm{E})$ Momordin I derivative (b) $(0,0.002,0.004,0.006,0.008 \mathrm{mM})$, respectively. All inhibitors were dissolved in DMSO. The first lane in the autoradiogram is a DMSO control (DMSO instead of inhibitors). $6 \%$ polyacrylamid native gel was used.

anhydride according to the published method ${ }^{8}$ resulting in momordin I derivatives (a) and (b) being successfully obtained (Fig. 2). For comparison data, curcumin, curcumin derivative $\mathrm{Cl}$, momordin $\mathrm{I}$, and momordin I derivatives (a) and (b) were concurrently assayed by EMSA. IC 50 values were calculated as a basis for quantitative analysis. As shown in Figures 3 and 4, momordin I derivatives showed remarkable inhibitory effects on the formation of Fos-JunAP-I DNA complex. $\mathrm{IC}_{50}$ values of momordin I derivatives for inhibition of the formation of Fos-Jun-AP-1 DNA complex were about $4.0 \mu \mathrm{M}$ in this experiment. This result means that momordin I derivatives are the most effective inhibitors by a factor of about 30 compared to momordin I (the $\mathrm{IC}_{50}$ value of momordin $\mathrm{I}$ is about $0.13 \mathrm{mM}$ ), and are moreover about 125 times more effective than curcumin (the $\mathrm{IC}_{50}$ value of curcumin is about $0.5 \mathrm{mM}$ ) ever published. From our previous report, the curcumin derivative $\mathrm{Cl}$ was shown to be very effective inhibitor. ${ }^{6}$ However, in this

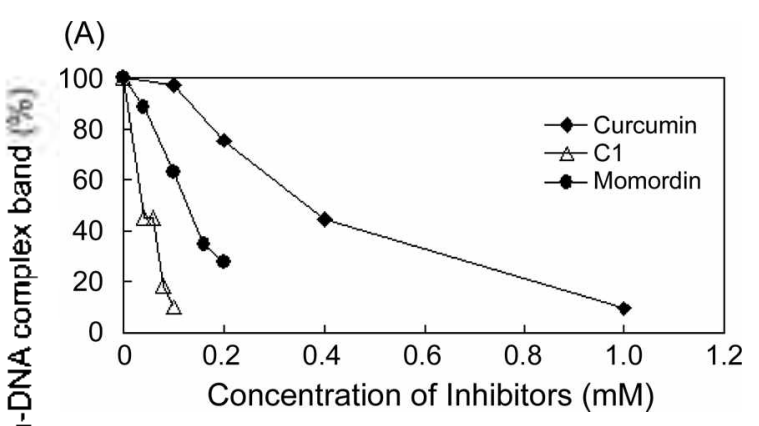

(B)

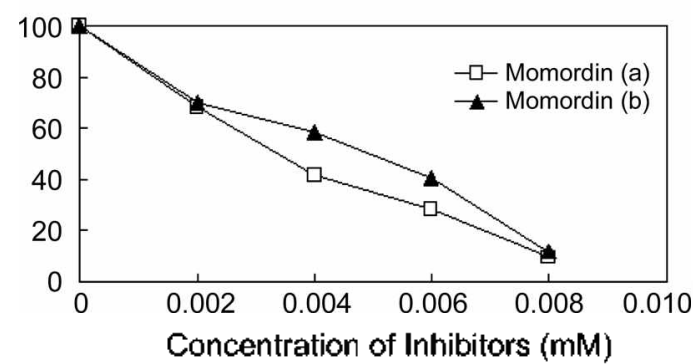

Figure 4. Activity in the formation of Fos-Jun- $\Lambda$ P-J $D N \Lambda$ complex decreased by increasing the inhibitor concentration. $(\Lambda)$ Curcumin, curcumin derivative $C 1$ and momordin I showed gradually decreased curves as the inhibitor concentration increases. (B) Momordin I derivatives (a) and (b) show exponentially decreasing curves at low concentration.

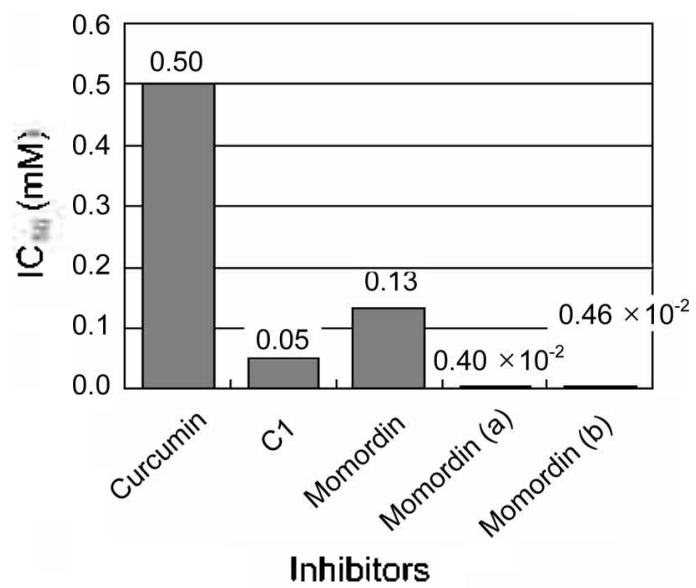

Figure 5. Comparisons of IC50 values in each chemical. Marked figures denote measured IC50 values (mM).

experiment, we found that momordin I derivatives are about 12 times more effective than the curcumin derivative $\mathrm{Cl}$. As shown in Figure 4, the curve illustrated that the increase in the inhibition activity as the concentration of curcumin, curcumin derivative $\mathrm{CI}$ and momordin I increased showed a gradually decreasing slope (Fig. 4-A). However, the curves illustrating the increases in the inhibition activity as the concentration of momordin I derivatives (a) and (b) increased showed an exponentially decreasing slope (Fig. 4B). That is, momordin I derivatives more easily reached the $\mathrm{IC}_{50}$ value at more low concentration than curcumin and momordin I did. So we finally concluded that momordin I derivatives were more efficient inhibitors of the formation of 
Fos-Jun-AP-1 DNA complex.

Ursolic acid, uvaol and momordin I derivatives have a similar chemical structure with little differences. Although there were only little differences, they showed quite different inhibitory activities. So this indicated that momordin I derivatives (a) and (b) have an specific inhibitory mechanism through chemical interactions with Fos-Jun heterodimer or AP-1 DNA sequences. To explore the mechanism of inhibitory effects on the formation of Fos-Jun-AP-1 DNA complex, further structural approaches are being investigated.

Acknowledgment. We thank the Ministry of Education \& Human Resources for the Brain Korea 21 fellowship to Juhyung Lee, Wook-Hwan Kim, Chi-Hoon Park, and Kyungchae Jeong and partial assistance for this research.

\section{References}

1. Angel, P.; Imagawa, M.; Chiu, R.; Stein, B.; Imbra, R.-J.;
RahmsdorS, H.-J.; Jonat, C.; Herrlich, P.; Karin, M. Cell 1987, $49(6), 729$.

2. Angel, P.; Karin, M. Biochim Bioph's Acta 1991, J072, 129.

3. Ammon, H.-P.; Wahl, M.-A. Planta Med. 1991, 57, 1 .

4. Lee, D.-K.; Yang, C.-H. Anticancer Res. 1998, $18,119$.

5. Park, S.; Lee, D.-K.; Yang, C.-H. Cancer Lett, 1998, 127, 23.

6. Hahm, E.-R.; Cheon, G.; Lee, J.; Kim, B.; Park, C.; Yang, C.-H. Cancer Lett. 2002, 184, 89.

7. Hahm, E.-R.; Gho, Y. S.; Park, S.; Park, C.; Kim, K.-W.; Yang, C.H. Biochem Biophys Res Commun. 2004, 321, 337.

8. Cristoni, A.; Nizzola, R; Malandrino, S. I/ Farmaco 1994, 49(4), 281.

9. Huang. T. S.; Lee, S. C.; Lin, J. K. Proc. Natl. Acad. Sci. USA $1991,88,5292$.

10. Kerppola, T. K.; Curran, T. Cell 1991, 66, 317.

11. Abale, C.; Luk, D.; Gentz, R.; Rauscher, F. J.; Curtan, T. Proc. Natl. Acad. Sci. USA 1990, 87, 1032.

12. Huang, M. T.; Wang, Z. Y; Georgiadis, C. A.; Laskin, J. D.; Conney, A. H. Carcinogenesis 1992, /3, 2183.

13. Yoon, S.-O.; Kim, M.-M.; Chung, A.-S. J Biol Chemi. 2001, 276, 20085.

14. Herron, G. S.; Banda, M. J.; Clark, E. J.; Gavrilovic, J.; Werb, Z.J. Biol. Chem. 1986, 261, 2814. 